\title{
KINETIC STUDIES OF COLOUR AND PHENOL REMOVAL FROM WASTEWATER USING MANGO SEED SHELL ACTIVATED CARBON
}

G. D. AKPEN, I. L. NWAOGAZIE AND T. G. LETON

(Received 28, January 2011; Revision Accepted 27, May 2011)

\begin{abstract}
Kinetic studies by batch technique were carried out using activated carbon prepared from mango seed shell for the adsorption of colour and phenol from wastewater. The data generated from the studies were used for kinetic modelling in order to determine the rate and mechanism of adsorption. The results revealed that adsorption was best fitted by the pseudo-second order model for both methylene blue $(\mathrm{MB})$ and phenol adsorptions. Intra-particle diffusion kinetic plots did not pass through the origin, indicating that intra-particle diffusion was not the only rate controlling mechanism. The results showed that mango seed shell activated carbon (MSSAC) is more effective for adsorption of colour than phenol in wastewater.
\end{abstract}

KEYWORDS: Kinetics, Adsorption, Mango seed shell, Colour, Phenol, Wastewater

\section{INTRODUCTION}

Adsorption is a time-dependent process and it is very important to know the rate of adsorption for design purposes. The rate and mechanism of adsorption is controlled by various factors like physical and/or chemical properties of adsorbent, ambient temperature, $\mathrm{pH}$ of medium and nature of adsorbate. The prediction of adsorption rate gives important information for designing adsorption systems. Kinetic models have been used to investigate the mechanism and the rate controlling steps of sorption which are helpful for selecting optimum operating conditions for the full-scale batch process.

Pseudo-first-order, pseudo-second-order, Elovich and intra-particle diffusion kinetic models have been used by various investigators. Among these are adsorption of basic red by Euphorbia Antiquorum $L$ wood based activated carbon (Sivakumar and Palanisamy, 2009), removal of $\mathrm{Cu}$ (II) ion from aqueous solution using sago waste as adsorbent (Maheswari et al, 2008); phenol removal from aqueous systems by tendu leaf refuse (Nagda et al, 2007); adsorption of phenol and dye from aqueous solution using chemically modified date pits activated carbons (Belhachemi and others, 2009) and adsorption of remazol black 5 on palm kernel shell activated carbon (Zawani et al, 2009).Others are the biosorption of zinc onto gallus domesticus shell powder ( Kalyani et al, 2009), adsorption of methylene blue onto gulmohar plant leaf powder ( Ponnusami et al, 2009), methylene blue (MB) removal from aqueous solution by adsorption on treated sawdust (Bello et al, 2010) among others.

This study is fashioned to determine the kinetics of adsorption of colour and phenol from wastewater using activated carbon prepared from mango seed shells as adsorbent. This will be achieved by calibrating kinetic models proposed in literature in order to understand the mechanism of adsorption of these pollutants by mango seed shell activated carbon (MSSAC).

G. D. Akpen, Department of Civil Engineering, University of Agriculture, Makurdi, Nigeria

I. L. Nwaogazie, Department of Civil and Environmental Engineering, University of Port Harcourt, Port Harcourt, Nigeria

T. G. Leton, Department of Civil and Environmental Engineering, University of Port Harcourt, Port Harcourt, Nigeria 
This study is of interest because knowledge of adsorption rate and mechanism is very important for selecting optimum operating conditions for design purposes.

\section{THEORETICAL CONSIDERATION}

Kinetics of adsorption, describing the solute uptake rate, which in turn governs the contact time of adsorption process, is one of the important characteristics defining the efficiency of adsorption (Patil et al, 2006). In order to investigate the mechanism of $\mathrm{MB}$ and phenol adsorption by mango seed shell based activated carbon (MSSAC), the following four kinetic models were considered:

\section{Pseudo-First-Order Model}

The pseudo-first-order rate expression based on solid capacity is generally expressed

as follows (Lagergren, 1898):

$$
\frac{d q_{t}}{d t}=K_{1}\left(q_{e}-q_{t}\right)
$$

Where, $\frac{d q_{t}}{d t}$ is the rate of adsorption, $q_{e}$ is the amount of adsorbate adsorbed at equilibrium $(\mathrm{mg} / \mathrm{g}), \mathrm{q}_{\mathrm{t}}$ is the amount adsorbed at any time $\mathrm{t}$ $(\mathrm{mg} / \mathrm{g}), \mathrm{k}_{1}$ is the rate constant of first order adsorption ( $\mathrm{l} /$ minutes). After integration and applying boundary conditions, $t=0$ to $t$ and $q_{t}=0$ to $\mathrm{q}_{\mathrm{t}}$; Equation (1) becomes:

$\log \left(\mathbf{q}_{\mathrm{e}}-\mathbf{q}_{\mathrm{t}}\right)=\log \left(\mathbf{q}_{\mathrm{e}}\right)-\frac{\mathrm{k}_{1}}{2}, 303 \mathrm{t}$

Values of adsorption rate constant $\left(k_{1}\right)$ for the adsorbate are determined from the straight line plot of $\log \left(q_{e}-q_{t}\right)$ against $t$. A high value of the correlation coefficient is an indication that the rate of removal of the adsorbate by the adsorbent follows the pseudo-first-order equation.

The parameter $\log \left(q_{e}\right)$ is an adjustable parameter and often it is found not equal to the intercept of a plot of $\log \left(q_{e^{-}}-q_{t}\right)$ against $t$, whereas in a true first order model, $\log \left(q_{e}\right)$ should be equal to the intercept of a plot of $\log \left(q_{e^{-}} q_{t}\right)$ against $t$. Therefore one has to find some means of extrapolating the experimental data to $t=\infty$, or treat $\mathrm{q}_{\mathrm{e}}$ as an adjustable parameter to be determined by trial and error. For this reason, it is necessary to use trial and error to obtain the equilibrium sorption capacity, $q_{e}$, to analyze the first order model kinetics (Ho and MCkay, 1998).

\section{Pseudo-Second-Order Model}

The pseudo-second-order equation is also based on the sorption capacity of the solid phase. It predicts the behaviour over the whole range of data. Furthermore, it is in agreement with chemisorption being the rate controlling step and is expressed as (Ho et al, 2000):

$\frac{d q_{t}}{d t}=k_{2}\left(q_{e}-q_{t}\right)^{2}$

Where, $k_{2}$ is the rate constant of second orderadsorption (g/mg.min). $\frac{\mathbf{d q}_{\mathrm{t}}}{\mathrm{dt}}, \mathrm{q}_{\mathrm{t}}, \mathrm{q}_{\mathrm{e}}$ and $\mathrm{t}$ are as defined under Equation 1. For the same boundary conditions as in Pseudo-first order model, the integrated form of Equation (3) becomes:

$$
\frac{\mathrm{t}}{\mathrm{q}_{\mathrm{t}}}=\frac{1}{\mathrm{k}_{2} \mathrm{q}_{\mathrm{e}}{ }^{2}}+\frac{1}{\mathrm{q}_{\mathrm{e}}} \mathrm{t}
$$

If the initial sorption rate, $\mathrm{h}(\mathrm{mg} / \mathrm{g}$. minutes $)$ at $\mathrm{t}=$ 0 is defined as:

$$
\mathbf{h}=\mathbf{k}_{2} \cdot \mathbf{q}_{\mathbf{e}}{ }^{2}
$$

Then Equations (4) and (5) become:

$$
\frac{\mathrm{t}}{\mathrm{q}_{\mathrm{t}}}=\frac{1}{\mathrm{~h}}+\frac{1}{\mathrm{q}_{\mathrm{e}}} \mathrm{t}
$$

Equation (6) does not have the disadvantage of the problem with assigning an effective $\mathrm{q}_{\mathrm{e}}$. If pseudo-second order kinetics are applicable, the plot of $t / q_{t}$ against $t$ of Equation (6) should give a linear relationship from which $\mathrm{q}_{\mathrm{e}}$ and $\mathrm{h}$ values will be determined from the slope and intercept of the plot respectively and there is no need to know any parameter beforehand (Ho and Mckay, 1998). $\mathrm{k}_{2}$ will then be determined from Equation (5).

\section{Elovich Model}

The Elovich equation is mainly applicable for chemisorption kinetics. The equation is often valid for systems in which the adsorbing surface is heterogeneous (Sivakumar and Palanisamy, 
2009). The Elovich model is generally expressed in linear form as:

$$
\mathrm{q}_{\mathrm{t}}=\frac{1}{\beta} \ln (\alpha \beta)+\frac{1}{\beta} \ln \mathrm{t}
$$

Where,

á is the initial adsorption rate ( $\mathrm{mg} / \mathrm{g}$ minutes) and â is the desorption constant and is related to the extent of surface coverage and the activation energy for chemisorption $(\mathrm{g} / \mathrm{mg})$. $\mathrm{q}_{\mathrm{t}}, \mathrm{q}_{\mathrm{e}}$ and $\mathrm{t}$ are as defined under Equation 1.A plot of $q_{t}$ against In $t$ gives a linear trend with a slope of (1/ â) and an intercept of $1 /$ â $\ln$ (á â).

\section{Intra-particle Diffusion Study}

The most commonly used technique for identifying the mechanism involved in the adsorption process is by using intra-particle diffusion model as proposed by Weber and Morris (Abdelwahab, 2007) thus:

$$
\mathrm{q}_{\mathrm{t}}=\mathrm{k}_{\mathrm{d}} \mathrm{t}^{1 / 2+\mathrm{I}}
$$

Where, $K_{d}$ is the intra-particle diffusion rate constant. $\mathrm{q}_{\mathrm{t}}$ and $\mathrm{t}$ are as defined under Equation 1. If intra-particle diffusion occurs, then a plot of $q_{t}$ against $t^{1 / 2}$ will be linear and the line will pass through the origin if intra-particle diffusion was the only rate limiting parameter controlling the process. Otherwise, some other mechanism such as external mass transfer is also involved. Values of I give an idea about the thickness of the boundary layer.

\section{MATERIALS AND METHODS}

$100 \mathrm{ml}$ of test samples of $\mathrm{pH} 7$ with initial methylene blue (MB) concentration of $87 \mathrm{Pt}-\mathrm{Co}$ units were measured in 6 different $500 \mathrm{ml}$ beakers. Specified adsorbent doses of $200 \mathrm{mg}$ were added to each beaker and stirred at 98 revolutions per minute (rpm) using electrically operated paddles of a flocculator (ESF 12/10 model). In the case of phenol, the carbon dose and $\mathrm{pH}$ used were respectively $1000 \mathrm{mg}$ and 8 , while the initial phenol concentration was $0.047 \mathrm{mg} / \mathrm{l}$. kinetic studies were performed at a constant room temperature of $34 \pm 2^{\circ} \mathrm{C}$. The preparation procedure and the characteristics of the mango seed shell activated carbon (MSSAC) are reported elsewhere (Akpen, 2011; Akpen et al, 2011).
Samples were taken at preset time intervals of 5 , $10,20,30,40,50,60,90$ and 120 minutes and $30,60,90,120,150$ and 180 minutes in the case of $\mathrm{MB}$ and phenol respectively. The contents were allowed to settle for 2 minutes and filtered through no. 42 filter paper prior to analysis in order to minimize interference of the carbon fines with the analysis. The residual concentrations of $\mathrm{MB}$ and phenol were analysed according to standard methods as specified in $\mathrm{HACH}$ Model DR/2000 Spectrophotometer operator's manual. The carbon particle size used was $150-850 \mu \mathrm{m}$ in the case of MB and 150-425 $\mu \mathrm{m}$ for phenol. The same procedures were repeated for other initial concentrations of 126, 181, 240 and 262 Pt-Co units in the case of MB and 0.069, 0.074, 0.114 and $0.123 \mathrm{mg} / \mathrm{l}$ in the case of phenol.

The amount of adsorption at time $t, q_{t}$, was calculated by:

$q_{t}=\frac{\left(C_{0}-C_{t}\right)}{m} V$

Where, $\mathrm{C}_{0}$ and $\mathrm{C}_{\mathrm{t}}$ are the liquid-phase concentration of pollutants at initial and any time $t$, respectively. $V$ is the volume of the solution, and $\mathrm{m}$ is the mass of dry adsorbent used.

\section{RESULTS AND DISCUSSION}

The data on kinetics of adsorption was processed to understand the dynamics of adsorption process in terms of the order of rate constant. A typical pseudo first-order plot for the adsorption of $M B$ by MSSAC is given in Fig.1. The calculated rate constants and $\mathrm{q}_{\mathrm{e}}$ values and the corresponding linear regression correlation coefficients, $r$ values for all the kinetic models are presented in Tables1-4. It is obvious fromTables 1-4 that, the first-order kinetic model did not fit well to the experimental data because the experimental and calculated values of the equilibrium removal capacity, $\mathrm{q}_{\mathrm{e}}$ were different even though the correlation coefficients were high (0.829-0.990). The pseudo first-order rate constant $k_{1}$ generally decreased with increase in initial MB concentration for all the experimental carbons except Dausha 1:2 adsorbent. For local $1: 2$ adsorbent, $k_{1}$ decreased from 0.154 to 0.039 $\mathrm{min}^{-1}$ when the initial MB concentration was increased from 87-262 Pt-Co units. 


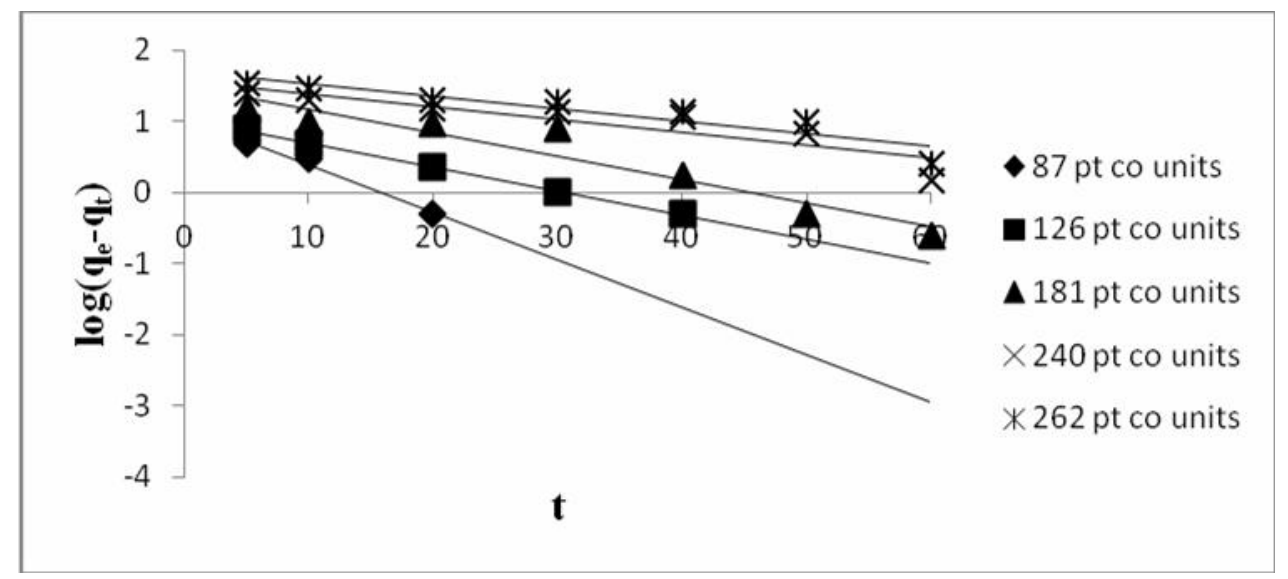

Fig. 1: Pseudo-First-Order Plots of MB Adsorption on local 1:2

A typical pseudo first-order plot for the adsorption of phenol by MSSAC is given in Fig.2. The corresponding parameters and coefficients are depicted in Table 5 . The correlation coefficients (r) ranged from 0.424 to 0.750 . Just as in the case of MB adsorption, first-order kinetic model did not fit well to the experimental data because the experimental and calculated values of the equilibrium removal capacity, $\mathrm{q}_{\mathrm{e}}$ were significantly different. Besides, the low $r$ values suggest that the adsorption data fitted poor to pseudo firstorder kinetics. Thus, the adsorption of phenol onto MSSAC does not follow the pseudo firstorder rate model.

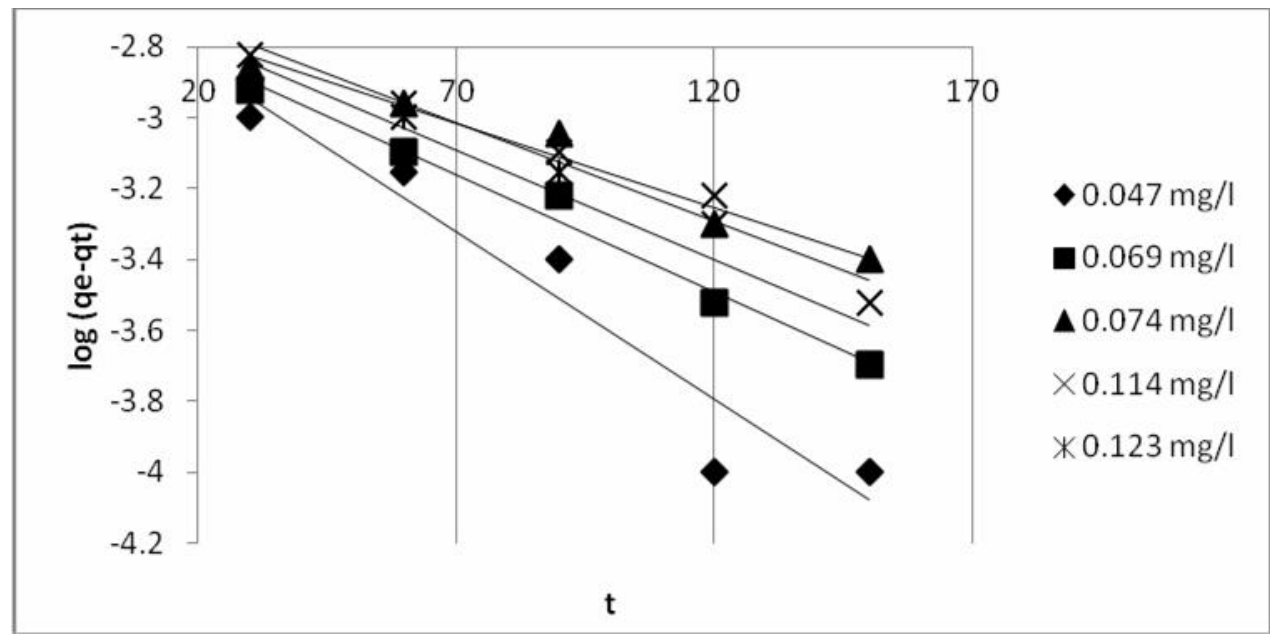

Fig. 2: Pseudo-First-Order Plots of Phenol Adsorption on local 1:2

Figs.3 shows a typical pseudo secondorder plot for the adsorption of MB by MSSAC at various initial concentrations and the corresponding second order kinetic rate constants and correlation coefficients are given in Tables 1-4. Unlike pseudo first order model, good correlation is observed between experimental data and the pseudo-second-order kinetic model with $r$ values generally higher than 0.99 . For the four variations of the mango seed shell activated carbons (MSSAC) studied, the differences between the experimental and the calculated 
values of the equilibrium removal capacity, $q_{e}$ were not significant. This suggests that the ratelimiting step in these biosorption systems may be chemisorptions involving valence forces through sharing or exchange of electrons between adsorbent and MB as reported by Ho and McKay (1999). The equilibrium sorption capacity, $q_{e}$ increase with increase in initial MB concentration while initial sorption rate, $\mathrm{h}$ generally decreased with increase in initial MB concentration for all the experimental activated carbons studied.
It can be noticed that the pseudo secondorder rate constant, $\mathrm{k}_{2}$ for Dausha 1:2 decreased from 0.0412 to 0.000743 (Pt-co units $/ \mathrm{mg} \mathrm{min}$ ) with increase in initial MB concentration from 87262 Pt-co units (see Table 1). The decrease in the rate of $\mathrm{MB}$ removal with increasing initial $\mathrm{MB}$ concentration may be due to decreasing MB diffusivity as a result of the association of dye molecules to form bulky aggregates which becomes more pronounced at high dye concentration. 
Table 1: Adsorption Kinetic Model Rate Constants for Dausha 1:2, at different Initial Concentrations of MB

\begin{tabular}{|c|c|c|c|c|c|c|c|c|c|c|c|c|c|c|}
\hline \multirow{2}{*}{$\begin{array}{l}\text { Initial } \\
\text { conc.(Pt- } \\
\text { Co } \\
\text { Units) }\end{array}$} & \multicolumn{4}{|c|}{ Pseudo First Order Model } & \multicolumn{4}{|c|}{ Pseudo Second Order Model } & \multicolumn{3}{|c|}{ Elovich Model } & \multicolumn{3}{|c|}{$\begin{array}{l}\text { Intra-particle Diffusion } \\
\text { Model }\end{array}$} \\
\hline & $\begin{array}{l}\mathrm{q}_{\mathrm{e}} \\
\text { (exp.) }\end{array}$ & $\begin{array}{l}\mathrm{q}_{\mathrm{e}} \\
\text { (cal.) }\end{array}$ & $\mathrm{K}_{1}$ & $\mathrm{r}$ & $\mathrm{h}$ & $q_{e}$ & $\mathrm{~K}_{2}$ & $r$ & $\alpha$ & $B$ & $\mathrm{r}$ & $\mathrm{K}_{\mathrm{d}}$ & $r$ & I \\
\hline 87 & 14.5 & 9.86 & 0.143 & 0.978 & 9.174 & 14.925 & 0.0412 & 0.999 & 263.39 & 0.634 & 0.858 & 0.480 & 0.723 & 10.51 \\
\hline 126 & 21.0 & 9.68 & 0.032 & 0.829 & 2.825 & 22.727 & 0.0055 & 0.997 & 22.02 & 0.310 & & 1.152 & 0.947 & 10.13 \\
\hline 181 & 30.17 & 37.93 & 0.0714 & 0.921 & 2.646 & 34.48 & 0.0022 & 0.993 & 10.0333 & 0.141 & 0.947 & 2.348 & 0.865 & 9.069 \\
\hline 240 & 40.0 & 54.33 & 0.069 & 0.975 & 2.762 & 47.62 & 0.00123 & 0.993 & 5.506 & 0.919 & & 3.643 & 0.901 & 7.401 \\
\hline 262 & 43.67 & 62.66 & 0.067 & 0.980 & 2.294 & 55.556 & 0.000743 & 0.980 & 4.789 & 0.0767 & 0.963 & 4.378 & 0.894 & 4.581 \\
\hline
\end{tabular}

Table 2: Adsorption Kinetic Model Rate Constants for Dausha 1:3 at different Initial Concentrations of MB

\begin{tabular}{|c|c|c|c|c|c|c|c|c|c|c|c|c|c|c|}
\hline \multirow{2}{*}{$\begin{array}{l}\text { Initial } \\
\text { conc.(Pt- } \\
\text { Co Units) }\end{array}$} & \multicolumn{4}{|c|}{ Pseudo First Order Model } & \multicolumn{4}{|c|}{ Pseudo Second Order Model } & \multicolumn{3}{|c|}{ Elovich Model } & \multicolumn{3}{|c|}{$\begin{array}{l}\text { Intra-particle Diffusion } \\
\text { Model }\end{array}$} \\
\hline & $q_{e}$ (exp.) & $q_{e}($ cal. $)$ & $\mathrm{K}_{1}$ & $r$ & $\mathrm{~h}$ & $q_{e}$ & $\mathrm{~K}_{2}$ & $r$ & $\alpha$ & $\mathrm{B}$ & $\mathrm{r}$ & $\mathrm{K}_{\mathrm{d}}$ & $r$ & $\mathrm{I}$ \\
\hline 87 & 14.5 & 10.07 & 0.053 & 0.977 & 2.192 & 15.625 & 0.00898 & 0.998 & 17.22 & 0.454 & 0.961 & 0.775 & 0.934 & 7.299 \\
\hline 126 & 21 & 19.06 & 0.044 & 0.950 & 2.075 & 22.73 & 0.0 & 0. & 9.401 & 0.271 & 0 . & 1.320 & 0.977 & 7.923 \\
\hline 181 & 29.67 & 13.61 & 0.025 & 0.977 & 3.984 & 31.26 & 0.00408 & 0.998 & 47.35 & 0.246 & 0.997 & 1.442 & 0.979 & 14.97 \\
\hline 240 & 37 & 36.64 & 0.023 & 0.990 & 1.065 & 50.0 & 0.00043 & 92 & 2.63 & 0.101 & 0.985 & 3.636 & 0.997 & -1.633 \\
\hline 262 & 36.67 & 37.84 & 0.021 & 0.979 & 0.658 & 71.429 & 0.0013 & 0.931 & 2.023 & 0.0922 & 0.974 & 3.973 & 0.986 & -5.630 \\
\hline
\end{tabular}


Table 3: Adsorption Kinetic Model Rate Constants for Local 1:2 at different Initial Concentrations of MB

\begin{tabular}{|c|c|c|c|c|c|c|c|c|c|c|c|c|c|c|}
\hline \multirow{2}{*}{$\begin{array}{l}\text { Initial } \\
\text { conc.(Pt- } \\
\text { Co Units) }\end{array}$} & \multicolumn{4}{|c|}{ Pseudo First Order Model } & \multicolumn{4}{|c|}{ Pseudo Second Order Model } & \multicolumn{3}{|c|}{ Elovich Model } & \multicolumn{3}{|c|}{$\begin{array}{l}\text { Intra-particle } \\
\text { Diffusion Model }\end{array}$} \\
\hline & $\begin{array}{l}\mathrm{q}_{\mathrm{e}} \\
\text { (exp.) }\end{array}$ & $\begin{array}{l}\mathrm{q}_{\mathrm{e}} \\
\text { (cal.) }\end{array}$ & $\mathrm{K}_{1}$ & $r$ & $\mathrm{~h}$ & $\mathrm{q}_{\mathrm{e}}$ & $\mathrm{K}_{2}$ & $r$ & $\alpha$ & $\beta$ & $r$ & $\mathrm{~K}_{\mathrm{d}}$ & $r$ & I \\
\hline 87 & 21.75 & 11.641 & 0.154 & 0.990 & 23.81 & 22.222 & 0.048 & 0.9995 & 54956.483 & 0.672 & 0.880 & 0.46 & 0.752 & 17.92 \\
\hline 126 & 31.75 & 11.015 & 0.078 & 0.998 & 20.408 & 32.258 & 0.020 & 0.9995 & 9172.321 & 0.393 & 0.935 & 0.813 & 0.828 & 24.52 \\
\hline 181 & 45.25 & 31.189 & 0.076 & 0.956 & 11.364 & 47.619 & 0.005 & 0.998 & 376.179 & 0.193 & 0.949 & 1.787 & 0.903 & 28.99 \\
\hline 240 & 60 & 35.975 & 0.039 & 0.894 & 8.13 & 66.667 & 0.002 & 0.997 & 98.389 & 0.119 & 0.971 & 3.005 & 0.964 & 30.68 \\
\hline 262 & 65.5 & 49.204 & 0.039 & 0.925 & 6.289 & 76.923 & 0.001 & 0.996 & 26.126 & 0.083 & 0.981 & 4.289 & 0.967 & 24 \\
\hline
\end{tabular}

Table 4: Adsorption kinetic model rate constants for Local 1:3 at different Initial Concentrations of MB

\begin{tabular}{|c|c|c|c|c|c|c|c|c|c|c|c|c|c|c|}
\hline \multirow{2}{*}{$\begin{array}{l}\text { Initial } \\
\text { conc.(Pt- } \\
\text { Co } \\
\text { Units). }\end{array}$} & \multicolumn{4}{|c|}{ Pseudo First Order Model } & \multicolumn{4}{|c|}{ Pseudo Second Order Model } & \multicolumn{3}{|c|}{ Elovich Model } & \multicolumn{3}{|c|}{$\begin{array}{l}\text { Intra-particle Diffusion } \\
\text { Model }\end{array}$} \\
\hline & $q_{e}($ exp. $)$ & $\mathrm{q}_{\mathrm{e}}$ (cal.) & $\mathrm{K}_{1}$ & $r$ & $\mathrm{~h}$ & $q_{e}$ & $\mathrm{~K}_{2}$ & $r$ & $\alpha$ & $\beta$ & $r$ & $\mathrm{~K}_{\mathrm{d}}$ & $r$ & 1 \\
\hline 87 & 21.75 & 9.48 & 0.055 & 0.986 & 6.757 & 22.73 & 0.013 & 0.995 & 258.028 & 0.416 & 0.973 & 0.798 & 0.893 & 14.55 \\
\hline 126 & 31.5 & 8.77 & 0.023 & 0.832 & 6.173 & 33.33 & 0.006 & 0.999 & 101.342 & 0.245 & 0.985 & 1.41 & 0.942 & 18.35 \\
\hline 181 & 45.25 & 22.336 & 0.051 & 0.981 & 10.526 & 47.62 & 0.005 & 0.995 & 109.135 & 0.160 & 0.965 & 2.088 & 0.890 & 26.48 \\
\hline 240 & 60 & 35.24 & 0.041 & 0.969 & 8.772 & 66.67 & 0.002 & 0.994 & 63.601 & 0.108 & 0.991 & 3.207 & 0.951 & 29.68 \\
\hline 262 & 65.5 & 47.97 & 0.035 & 0.938 & 5.78 & 76.92 & 0.001 & 0.995 & 21.386 & 0.08 & 0.984 & 4.466 & 0.971 & 21.99 \\
\hline
\end{tabular}


The correlation coefficients, $r$ ranged from 0.980 to 0.999 , which is higher than pseudo first-order values $(0.829-0.980)$. From these results it can be suggested that pseudo second-order describes the adsorption of MB by MSSAC better than pseudo first order model. Similar results were reported by Sivakumar and Palanisamy (2009) on the adsorption of basic red 29 by euphorbia antiquorum $L$ based activated carbon. The same behaviour was observed by Bello et al (2010) for the adsorption of methylene blue onto treated saw dust.

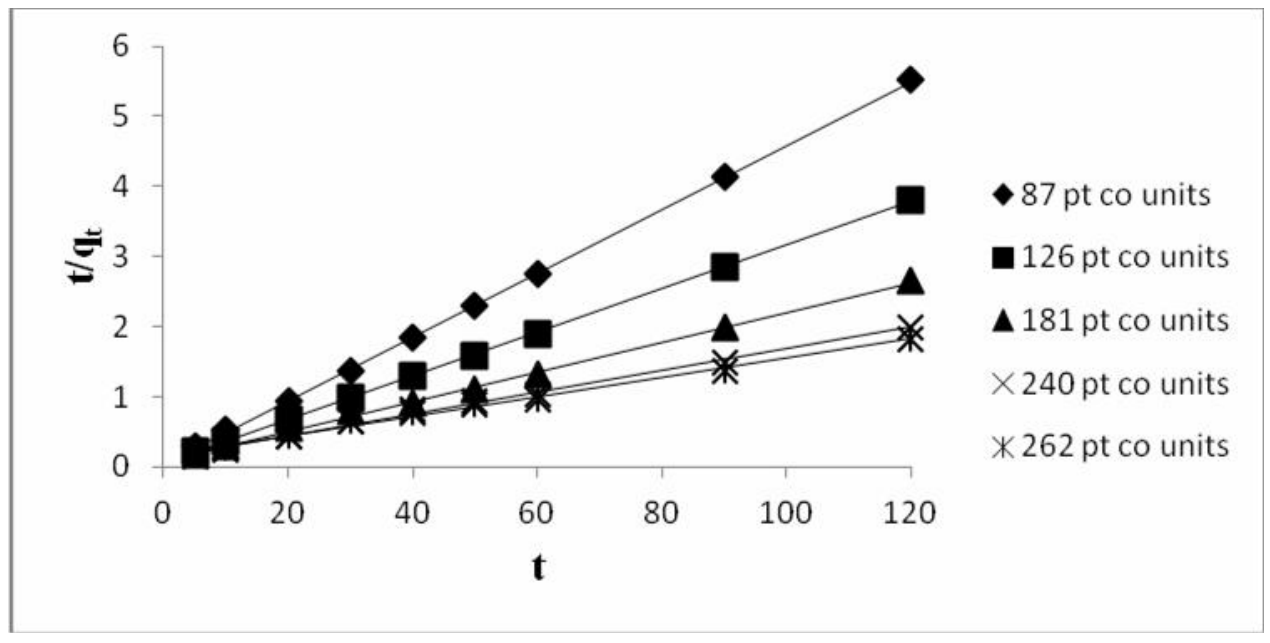

Fig. 3: Pseudo-Second-Order Plots of MB Adsorption on local 1:2

In the case of phenol adsorption, a typical second order plot is presented in Fig.4, while the adsorbent parameters and correlation coefficients are shown in Table 5. The high values of the rate constant $\mathrm{k}_{2} \quad(8.75-18.79)$ and correlation coefficients, $r$ (0.997-0.999) suggest that the kinetics of phenol adsorption follows the pseudosecond order kinetic model.

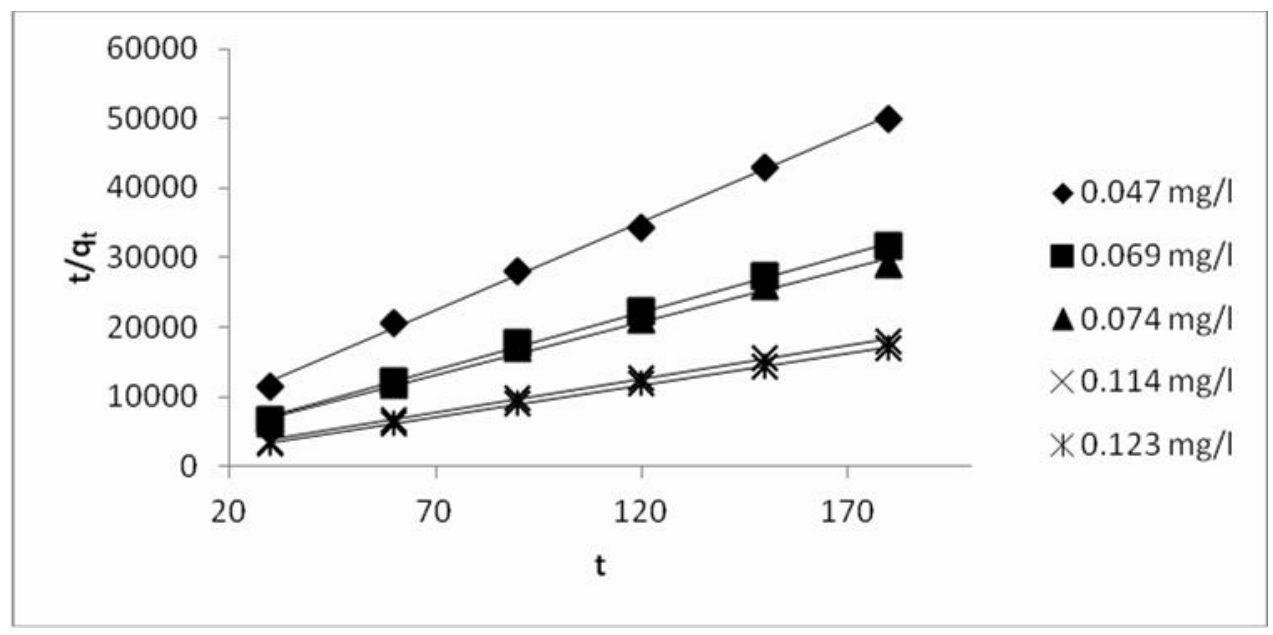

Fig. 4: Pseudo-Second-Order Plots of Phenol Adsorption on local 1:2 
A typical Elovich plot for the adsorption of MB by MSSAC at various initial dye concentrations is given in Fig.5. The plots are linear with good correlation coefficients $(r=0.858$ to 0.997$)$. The initial adsorption rate, á, increased, while desorption constant, â decreased with increase in initial dye concentration for all the experimental activated carbons (see Tables 1-4). The increase in the values of á can be attributed to an increase in the driving force for mass transfer, i.e. more $\mathrm{MB}$ molecules are able to reach the surface of the adsorbent in a shorter period of time.

Table 5: Adsorption Kinetic Model Rate Constants for Dausha 1:2, Local 1:2 and Local 1:3 at different Initial Concentrations of Phenol

\begin{tabular}{|c|c|c|c|c|c|c|c|c|c|}
\hline \multirow[t]{2}{*}{ Adsorbent } & \multirow{2}{*}{$\begin{array}{l}\text { Initial } \\
\text { Conc. } \\
\text { (Mg/l) }\end{array}$} & \multicolumn{4}{|c|}{ Pseudo-First Order Model } & \multicolumn{4}{|c|}{ Pseudo-Second Order Model } \\
\hline & & $\begin{array}{l}\mathrm{q}_{\mathrm{e}} \\
\text { (exp.) }\end{array}$ & $\begin{array}{l}\mathrm{q}_{\mathrm{e}} \\
\text { (cal.) }\end{array}$ & $\mathrm{K}_{1}$ & $r$ & $\mathrm{~h}$ & $q_{e}$ & $\mathrm{~K}_{2}$ & $r$ \\
\hline \multirow{5}{*}{$\begin{array}{l}\text { Dausha } \\
1: 2\end{array}$} & 0.047 & 0.0033 & $\begin{array}{l}9.75 x \\
10^{-5}\end{array}$ & -0.0253 & 0.4313 & 0.000143 & 0.00375 & 10.14 & 0.998 \\
\hline & 0.069 & 0.0052 & $\begin{array}{l}2.52 \times \\
10^{-5}\end{array}$ & -0.0507 & 0.750 & 0.000434 & 0.00556 & 14.01 & 0.999 \\
\hline & 0.074 & 0.0057 & $\begin{array}{l}8.99 \times \\
10^{-5}\end{array}$ & $\overline{0}-00364$ & 0.500 & 0.000502 & 0.00598 & 14.03 & 0.998 \\
\hline & 0.114 & 0.0094 & $\begin{array}{l}7.36 \times \\
10^{-5}\end{array}$ & -0.0299 & 0.562 & 0.00171 & 0.00953 & 18.79 & 0.999 \\
\hline & 0.123 & 0.0101 & $\begin{array}{l}9.89 \times \\
10^{-5}\end{array}$ & -0.0276 & 0.508 & 0.00160 & 0.01034 & 14.97 & 0.999 \\
\hline \multirow{5}{*}{ Local 1:2 } & 0.047 & 0.0036 & $\begin{array}{l}7.74 \times \\
10^{-5}\end{array}$ & -0.0253 & 0.424 & 0.00021 & 0.00396 & 13.37 & 0.998 \\
\hline & 0.069 & 0.0057 & $\begin{array}{l}1.02 \times \\
10^{-4}\end{array}$ & -0.0253 & 0.486 & 0.000458 & 0.00603 & 12.61 & 0.999 \\
\hline & 0.074 & 0.0067 & $\begin{array}{l}1.37 \times \\
10^{-4}\end{array}$ & -0.0276 & 0.527 & 0.000406 & 0.00655 & 9.45 & 0.996 \\
\hline & 0.114 & 0.0100 & $\begin{array}{l}1.47 \times \\
10^{-4}\end{array}$ & -0.0253 & 0.506 & 0.00111 & 0.0103 & 10.37 & 0.999 \\
\hline & 0.123 & 0.0106 & $\begin{array}{l}1.23 \times \\
10^{-4}\end{array}$ & -0.0253 & 0.492 & 0.00148 & 0.0109 & 12.44 & 0.999 \\
\hline \multirow{5}{*}{ Local 1:3 } & 0.047 & 0.0035 & $\begin{array}{l}8.26 \times \\
10^{-5}\end{array}$ & -0.0253 & 0.458 & 0.000192 & 0.00384 & 13.01 & 0.999 \\
\hline & 0.069 & 0.0055 & $\begin{array}{l}1.07 \times \\
10^{-4}\end{array}$ & -0.0253 & 0.475 & 0.000399 & 0.000588 & 11.56 & 0.999 \\
\hline & 0.074 & 0.0059 & $\begin{array}{l}1.44 \times \\
10^{-4} \\
\end{array}$ & -0.0253 & 0.502 & 0.000351 & 0.000633 & 8.75 & 0.997 \\
\hline & 0.114 & 0.0096 & $\begin{array}{l}1.37 \times \\
10^{-4} \times\end{array}$ & -0.0276 & 0.526 & 0.00105 & 0.00989 & 10.73 & 0.998 \\
\hline & 0.123 & 0.0103 & $\begin{array}{l}1.13 x \\
10^{-4}\end{array}$ & -0.0276 & 0.497 & 0.00149 & 0.0106 & 13.33 & 0.999 \\
\hline
\end{tabular}




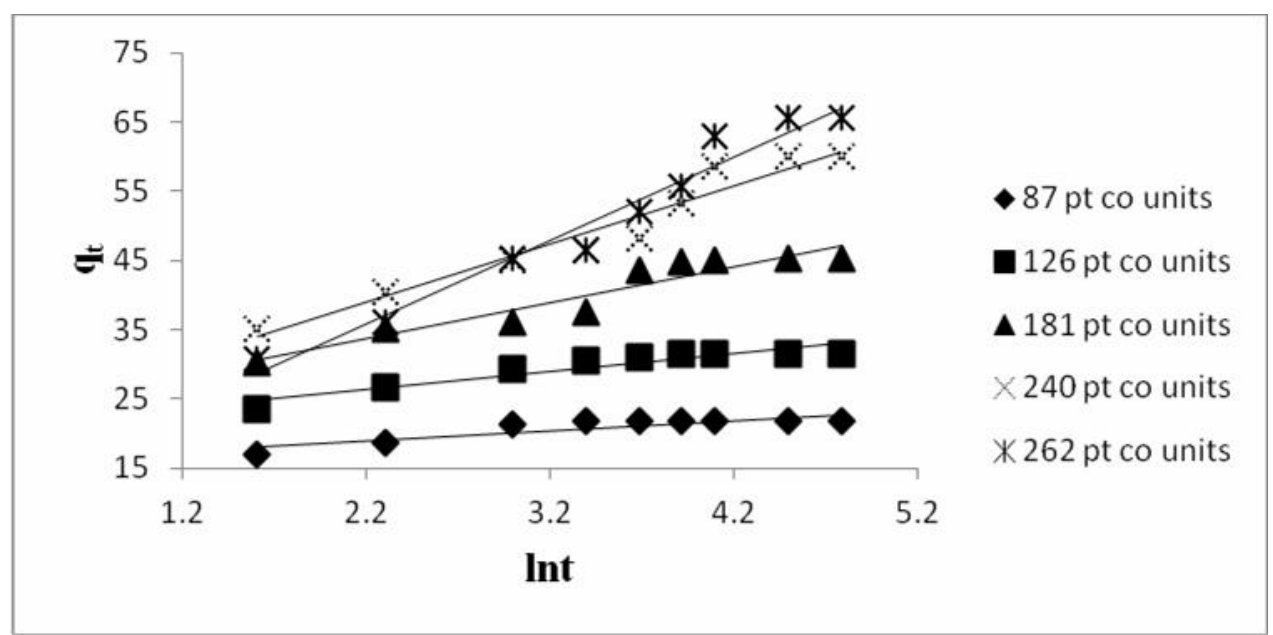

Fig. 5: Elovich Model Plots of MB Adsorption on local 1:2

Fig.6 depicts a typical intra-particle kinetic plot for the four experimental carbons with respect to MB adsorption. If intra-particle diffusion occurs, then a plot of $q$ against $t^{1 / 2}$ will be linear and the line will pass through the origin if the intra-particle diffusion was the only rate limiting parameter controlling the process. However, for this present study, the linear plots for a wide range of contact times do not pass through the origin. This deviation from the origin may be due to the variation of mass transfer in the initial and final stages of adsorption (Sivakumar and Palanisamy, 2009). This indicates that although intra-particle diffusion was involved in the adsorption process, it was not the sole sorption rate-controlling step. This also confirms that adsorption of MB on the adsorbent was a multistep process, involving adsorption on the external surface and diffusion into the interior.

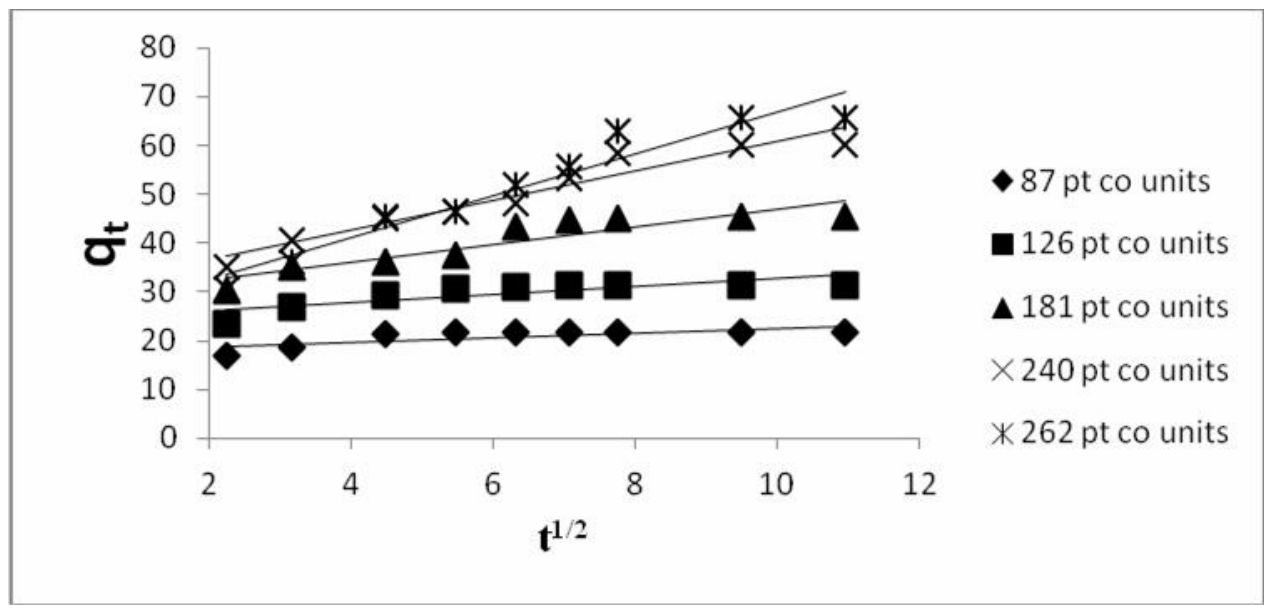

Fig. 6: Intra-particle Diffusion plots of MB adsorption on Local 1:2

The intra-particle diffusion rate, $\mathrm{k}_{\mathrm{d}}$ and the linear correlation coefficients are presented in Tables14. Values of $k_{d}$ decreased with increase in initial $\mathrm{MB}$ concentration and ranged from $0.48-4.466$. In general high $k_{d}$ values illustrate a better adsorption mechanism, which is related to an improved bounding between the $\mathrm{MB}$ and the adsorbent particles (Demirbas et al, 2004). The 
kinetic data obtained for Dausha $1: 3$ fits the intra-particle diffusion model better given the high correlation coefficients $(r=0.934-0.997)$ obtained. On the other hand, the intercept of the plots, I reflect the thickness of the boundary layer Abdelwahab (2007). The larger the intercept, the greater is the contribution of the surface sorption in the rate-limiting step (El-Latif et al, 2010).

\section{CONCLUSION}

Kinetic studies were carried out using activated carbons prepared from mango seed shell on the adsorption of colour and phenol from wastewater. Kinetic data generated from these studies were used for kinetic modelling in order to determine the rate and mechanism of adsorption.

Adsorption was best fitted by the pseudosecond order kinetic model for both colour and phenol adsorptions with correlation coefficients, $r$ generally greater than 0.99 for all the experimental carbons studied. This suggests that the rate-limiting step may be chemisorptions involving valence forces through sharing or exchange of electrons between adsorbent and MB. The mechanism of adsorption was rather complex and is probably a combination of external mass transfer and intra-particle diffusion given that the linear intra-particle diffusion kinetic plots do not pass through the origin. These results revealed that MSSAC is more effective for the adsorption of colour than phenol from wastewater.

\section{REFERENCES}

Abdelwahab, O., 2007. "Kinetic and Isotherm Studies of Copper (II) Removal from Wastewater using various Adsorbents" Egyptian JournaL of Aquatic Research. 33, (1): 125-143.

Akpen, G. D., 2011. "Mango Seed Shell Based Activated Carbon for Wastewater Treatment. PhD Thesis, Department of Civil and Environmental Engineering, University of Port Harcourt, Port Harcourt, Nigeria.

Akpen, G. D., Nwaogazie, I. L and Leton, T. G., 2011. "Optimum Conditions for the Removal of Colour from Wastewater by Mango Seed Shell based Activated Carbon" Indian J.Sci.Technol. 4, (8): 890-894.
Belhachemi, M., Belala, Z., Lahcene, D and Addoun, F., 2009. "Adsorption of Phenol and Dye from Aqueous Solution using Chemically Modified Date pits Activated Carbons". Desalination and Water Treatment 7, 182-190.

Bello, O. S., Adelaide, O. M., Hammed, M. A and Popoola, O. A. M., 2010. "Kinetic and Equilibrium Studies of Methylene Blue Removal from Aqueous Solution by Adsorption on Treated Sawdust". Macedonian Journal of Chemistry and Chemical Engineering, 29, (1): 77-85.

Demirbas, E., Kobya, M., Senturk, E and Ozkan, T., 2004. "Adsorption Kinetics for the Removal of Chromium (VI) from Aqueous Solutions on the Activated Carbons prepared from Agricultural Wastes". Water SA 30, (4): 533-539.

El-Latif, M. M. A., Ibrahim, A. M and El-Kady, M. F., 2010. "Adsorption Equilibrium, Kinetics and Thermodynamics of Methylene Blue from Aqueous Solutions using Biopolymer Oak Sawdust Composite". Journal of American Science; 6, (6): 267-283.

HO, Y. S and McKAY, G., 1998. "A Comparison of Chemisorption Kinetic Models Applied to Pollutant Removal on Various Sorbents". Trans IChemE, 76, Part B, 32340.

Ho, Y. S and McKay, G., 1999. "Pseudo-second order model for sorption processes". Process. Biochem. 34, 451-465.

Ho, Y. S., McKay, G., Wase, D. A. J and Foster, C. F., 2000. "Study of the Sorption of Divalent Metal ions on to Peat", Adsorp. Sci. Technol. 18, 639-650.

Kalyani, G., Rao, G. B., Saradhi, B. V and Kumar, Y. P., 2009. "Equilibrium and Kinetic Studies on Biosorption of Zinc onto Gallus Domesticus Shell Powder". ARPN Journal of Engineering and Applied Sciences 4, (1): 39-49.

Maheswari, P., Venilamani, N., Akrishnan, S. M., Shabudeen, P. S. S., Venckatesh, R and Pattabhi, S., 2008. "Utilization of Sago Wastes as 
an Adsorbent for the Removal of $\mathrm{Cu}$ (II) ion from aqueous solution." E-Journal of Chemistry. 5, (2): 233-242.

http/www.e-journals.net

Nagda, G. K., Diwan, A. M and Ghole, V. S., 2007. "Potential of Tendu Leaf Refuse for Phenol Removal in Aqueous Systems". Applied Ecology and Environmental Research 5, (2): 1-9.

Patil, S. J., Bhole, A. G and Natarajan, G. S., 2006. "Scavenging of $\mathrm{Ni}(\mathrm{II})$ metal ions by Adsorption on PAC and Babhul Bark". Journal of Environ. Science and Engg. 48, (3): 203-208.

Ponnusami, V., Aravindhan, R., Karthik raj, N., Ramadoss, G and Srivastava, S. N., 2009. "Adsorption of Methylene blue onto Gulmohar Plant Leaf Powder: Equilibrium, Kinetic, and Thermodynamic Analysis". Journal of Environ. Protection Science, 3, 1-10.

Sivakumar, P and Palanisamy, P. N., 2009. "Adsorption Studies of Basic Red 29 by a Non-Conventional Activated Carbon Prepared from Euphorbia Antiquorum L". International Journal of ChemTech Research, CODEN ( USA): Vol.1, No.3, pp 502-510,

Zawani, Z., Luqman, C. A and Thomas, S. Y. C., 2009. "Equilibrium, Kinetics and Thermodynamic Studies: "Adsorption of Remazol Black 5 on the Palm Kernel Shell Activated Carbon" European Journal of Scientific Research, 37, (1): 67-76.

http://www.eurojournals.com/ejsr.htm 